\title{
The role of brown adipose tissue in diet-induced thermogenesis
}

\section{By Michael J. Stock, Department of Physiology, St George's Hospital Medical School, University of London, Tooting, London SWI7 ORE}

It is somewhat remarkable that the importance of brown fat and diet-induced thermogenesis (DIT) in energy metabolism both gained prominence at more or less the same time, after both had remained obscure and ignored for many years. The concept of DIT (in its earlier guise of Luxuskonsumption) dates back to the turn of this century, while that of brown adipose tissue (BAT) has even earlier origins, dating back over 300 years. The importance of BAT as an effector of non-shivering thermogenesis (NST) began to emerge in the $1960 \mathrm{~s}$, but it was not until 1978 that its full thermogenic potential was realized (Foster \& Frydman, 1978).

DIT received even less attention than BAT, and it is only in the last decade that it has emerged as an important adaptive component in the regulation of energy balance. However, an early intimation of a connection between DIT and brown fat came from a study (Stirling \& Stock, 1968) that suggested that rats exhibiting DIT were similar in several respects to rats exhibiting cold-induced NST. One of these similarities, the increased thermogenic response to injections of noradrenaline, suggested that DIT, like NST, involved increases in sympathetic activity. It was not until over a decade later that it was proposed (Rothwell \& Stock, 1979) that the increased sympathetic activity resulted in activation of BAT thermogenesis, and that this was the source of DIT. Since 1979 , there have been numerous studies relating brown fat function to various dietary influences, and the role of defective BAT function in the aetiology of obesity. Developments in the area have now reached a point where there are now several novel BAT-selective adrenergic agonists being developed by the pharmaceutical industry for the treatment of obesity (Arch, 1989; Holloway, 1989).

The widespread interest and rapid developments in this area are both gratifying and reassuring to the relatively few groups that actively contributed to the early research on thermogenesis, BAT and obesity. However, the importance of DIT and the contribution of brown fat to DIT have been highly controversial topics (e.g., Hervey \& Tobin, 1983; Cox \& Lorden, 1986; Ma et al. 1987; Maxwell et al. 1988). This is not entirely unexpected since most new ideas tend to generate controversy, and it is important constantly to assess developments and fresh experimental findings as they arise. Thus, the object of the present presentation will be to consider to what extent the original proposal (Rothwell \& Stock, 1979) concerning the role of brown fat in DIT is still justified.

Before considering the evidence in detail, it should be noted that there are two major difficulties that tend to frustrate a clear interpretation of results from many experimental studies. The first is that, due to both conceptual and technical difficulties, it is not an easy task to assess levels of DIT. The other problem is that the quantitative assessment of BAT thermogenesis in vivo is also very difficult and demanding, and relies heavily on measurements on the most accessible brown fat depots. Furthermore, these measurements are usually made under conditions that do not equate to the animal's normal physiological status, where the level of DIT may be quite different from that at the time the BAT assessment is made.

\section{Evidence for DIT}

DIT strictly refers to those adaptive changes in heat production that play a regulatory role in maintaining energy balance and body composition. It differs from what is 
sometimes termed obligatory DIT in that it does not depend on, or relate to, the energy cost of digesting, absorbing, assimilating and utilizing ingested nutrients to meet the requirements for maintenance, growth and production of fat, progeny, milk, etc. Given a defined energy and nutrient intake, and a fixed requirement for maintenance, growth and production, the obligatory DIT should be predictable, and dependent on the stoichiometric and thermodynamic constraints on the various intermediary processes involved. Agricultural nutritionists have devised various empirical models that take account of this obligatory form of DIT, and can predict the partitioning of ingested energy into maintenance, growth, production, etc. However, the animal nutritionist is dealing with strains of species (cattle, sheep, pigs, etc.) that have been highly selected over numerous generations for rapid, efficient and consistent growth and energy utilization. In other, less efficient species with a highly variable genetic background, the large intra- and inter-individual variations in energetic efficiency cannot be accounted for in terms of obligatory DIT. In order to account for this variability in the efficiency of energy utilization, it has been necessary to invoke, and subsequently confirm, the existence of an adaptive form of DIT that dissipates energy consumed in excess of requirements. Unlike obligatory DIT, this adaptive form of heat production could be considered to have a homeostatic function in the regulation of energy balance, rather like the role of NST in the regulation of body temperature.

The problems of defining and quantifying adaptive DIT have been discussed at some length previously (Rothwell \& Stock, 1986a), but in experimental terms the task becomes one of partitioning energy expenditure into the various avenues that can be measured or estimated, and then assuming that the residual expenditure represents adaptive DIT. The problem with this, as with any estimation 'by difference', is that the reliability of the estimate is highly dependent on the level of experimental error relative to the size of the difference. One way to minimize this effect is to conduct experiments where the level of DIT represents a large and significant proportion of the total energy expenditure. This explains why so much of the experimental work on DIT has been carried out on dietary models of hyperphagia (e.g. the 'cafeteria' diet) and nutrient imbalance (e.g. protein deficiency), where levels of DIT can reach two to three times those in control animals.

The partitioning of DIT into its obligatory and adaptive components requires full and very precise measurements of energy balance and changes in body composition. Very few workers have been prepared to undertake all these measurements, and have generally relied on some less direct assessment, such as changes in resting metabolic rate, or the degree to which metabolic rate is depressed by $\beta$-adrenergic antagonists. By themselves, these tests can be considered as only a very approximate guide to changes in adaptive DIT, and should be treated cautiously. Some of these are listed in Table 1, together with more reliable indices of DIT.

Table 1. Six criteria for diet-induced thermogenesis in hyperphagic animals

1. Increased energy expenditure.

2. Decreased gross energetic efficiency.

3. Decreased net energetic efficiency.

4. Increased adaptive diet-induced thermogenesis.

5. Percentage of excess energy intake expended as heat exceeds net efficiency of normophagic control animals.

6. Increased sympathetic ( $\beta$-blockable) component to metabolic rate. 
Unless experiments are deliberately designed to maximize the adaptive DIT component, it is considered essential to utilize as many of these criteria as possible. This is not always possible (e.g. criterion 5 in Table 1 only applies to hyperphagic animals), but unless one has established a rigorous experimental model based on these criteria, any studies on the metabolic or tissue effectors of DIT could be misleading, or even meaningless (e.g. Maxwell et al. 1988).

In the course of many experiments, most of these criteria have been satisfied for both the hyperphagic (i.e. cafeteria-fed) and the nutrient imbalance (i.e. protein-deficient) rat models of DIT. Examples for both models are shown in Table 2, where it should be noted that nearly all (five out of six) the criteria for DIT are fulfilled. In these two examples, the level of adaptive DIT in the cafeteria-fed and protein-deficient rats is between three and four times the level of their respective controls.

These same criteria have also been applied to the results obtained by other workers, and only if the presence of elevated levels of adaptive DIT was obvious has the evidence for a brown fat involvement been considered. It is worth noting that differences in DIT arise not only in the experimental dietary models that increase DIT (e.g. cafeteria or low-protein diets), but also in the various examples of experimental and genetic obesity where it is the control (i.e. lean) animals that show the higher rates of DIT, rather than the experimental (obese) groups.

As mentioned earlier, it has proved very difficult to obtain reliable estimates of the quantitative importance brown fat plays in DIT, and much of the evidence relies on comparing biochemical and other correlates of BAT function with changes in either NST or DIT. There are many possible pitfalls to this approach, particularly as qualitative changes in BAT activity need not necessarily indicate a causal relationship with whole-body rates of heat production; the uncertainty will be compounded by using inadequate or insufficient indices of DIT (see previous discussion). A further problem is that DIT, unlike NST, is much more susceptible to inhibitory influences, such as stress. Given that maintenance of homeothermy is probably more important to survival than maintenance of energy balance (at least acutely), it is perhaps not surprising that thermogenesis can be still activated by a cold stimulus, but not by a dietary stimulus, even after surgical anaesthesia and the major invasive techniques that have been used in

Table 2. Summary of energy balance values $(k J / d)$ from two experiments where rats were fed on a cafeteria or a low-protein diet (values from Rothwell \& Stock (1982b) and Rothwell et al. (1983))

$\begin{array}{lcccc}\text { Diet ... } & \text { Control } & \text { Cafeteria } & \text { Control } & \text { Low-protein } \\ \text { Intake } & 208 & 361 & 248 & 263 \\ \text { Gain } & 33 & 49 & 71 & 56 \\ \text { Expenditure } & 175 & 311^{*} & 177 & 207^{*} \\ \text { Gross efficiency (\%) } & 16 & 14 & 29 & 21 \\ \text { Maintenance } & 111 & 116 & 114 & 93 \\ \text { Net efficiency (\%) } & 34 & 20^{*} & 53 & 33^{*} \\ \text { Total DIT } & 64 & 195 & 63 & 114 \\ \text { Obligatory DIT } & 20 & 22 & 43 & 22^{*} \\ \text { Adaptive DIT } & 44 & 173^{*} & 20 & 92^{*} \\ \text { Percentage excess intake expended } & - & 89^{*} & - & (200)^{*} \\ \text { B-Blockable } V_{\mathrm{O}_{2}}(\%) & 4 \cdot 1 & 27 \cdot 0^{*} & 5 \cdot 2 & 24 \cdot 4^{*}\end{array}$

DIT, diet-induced thermogenesis; $V_{O_{2}}$, oxygen consumption. *Indicates criteria for DIT (see Table 1) that differ significantly from control values. 
attempts to assess the BAT contribution in vivo to whole-body rates of thermogenesis (e.g. Ma et al. 1989).

\section{Effects of DIT on brown fat}

In rats exhibiting high levels of DIT, some of the most obvious changes in BAT are in the appearance and composition of the tissue. Various depots, but particularly the interscapular BAT, are darker and larger, and contain more protein and mitochondria as well as more adipocytes (Rothwell \& Stock, 1979; Tulp, 1981; Brooks et al. 1982). The hyperplastic response is interesting, since in young rats it appears to be permanent and is associated with lower levels of obesity in later life (Rothwell \& Stock 1982a). The increase in BAT protein occurs even in protein-deficient rats exhibiting DIT, and rates of tissue protein synthesis are unaffected in BAT, whereas other tissues (e.g., liver) show the expected decrease (Emery et al. 1983). This suggests that maintenance of BAT function is a very important component of the metabolic adaptation to low-protein diets. Changes in the sympathetic activation of BAT are evident from measurements of tissue noradrenaline turnover (Young et al. 1982), adipocyte respiration (Rothwell et al. 1987), lipolysis (Brooks et al. 1980) and their responses to adrenergic agonists (Rothwell et al. 1987). Changes in adrenoceptor number and profile (Rothwell et al. 1985) also occur, and the activity of most enzymes and pathways in intermediary metabolism increase.

As one might expect, it is the BAT mitochondria that show the most important and striking responses. Mitochondrial density, respiratory capacity (e.g. cytochrome $c$ oxidase ( $E C$ 1.9.3.1) activity) and in vitro respiration are all increased (Brooks et al. 1980; Himms-Hagen et al. 1981; Trayhurn et al. 1982b), but it is the changes in the proton conductance pathway (Nicholls, 1979) that relate directly to the thermogenic function of the tissue. Changes in mitochondrial GDP-binding (a reliable and routine method to assess changes in thermogenic activity) are well described and are too numerous to list. However, just as important are the increases seen in the amount of the uncoupling protein (Ashwell et al. 1984; Nedergaard et al. 1984) and the expression (mRNA levels) of the gene for the uncoupling protein (Falcou et al. 1985). Finally, all these changes in tissue activity are reflected in the in vivo thermogenic activity of BAT.

One of the most obvious and consistent changes seen in rats exhibiting DIT is the increase in the thermogenic response to noradrenaline (Rothwell \& Stock, 1979, 1982b; Rothwell et al. 1982), and measurements of tissue blood flow and oxygen extraction have shown that BAT accounts for virtually all the enhanced thermogenic capacity of rats exhibiting DIT (Rothwell \& Stock, 1981a). Additional evidence for a BAT contribution to DIT comes from the observation that carbohydrate meals produce larger thermogenic responses and larger increases in BAT blood flow than isoenergetic fat meals (Glick et al. 1984). In other words, the acute thermic response to meals of individual nutrients is related to their effect on BAT blood flow, and there is good evidence to indicate that BAT blood flow is directly related to the tissue's metabolic activity (Foster \& Depocas, 1980; Rothwell et al. 1984).

\section{Effects of brown fat activity on DIT}

Another way of assessing a tissue's contribution to a physiological function is to see how that function is affected by experimental, or natural changes in the size or activity of that tissue. Apart from dietary stimuli (e.g., hyperphagia, protein deficiency) which obviously affect DIT and energy balance directly, there are several other procedures that produce increases in BAT activity, and, therefore, that one would expect to influence the capacity of DIT. Cold acclimation is an obvious example, and it has been shown that 
cold-acclimated rats exhibit greater thermic responses to meals, adapt faster and with larger increases in DIT when overfed in a warm environment (Rothwell \& Stock, 1981b) and show marked reductions in energetic efficiency (Smith \& Romsos, 1984).

Adrenalectomy of genetically obese rats arrests the development of obesity and results in a very marked reactivation of BAT function (Holt \& York, 1982; Marchington $e$ t al. 1986). This is accompanied by a restoration of normal thermic responses to feeding, and levels of metabolic efficiency decrease to values similar to those of lean animals. Likewise, administration of $\beta$-adrenergic drugs that are highly selective agonists of BAT (Arch et al. 1984) cause reductions in body-weight and fat, and increases in heat production in obese animals (Arch \& Ainsworth, 1983). Thus, increases in BAT activity induced by cold, adrenalectomy and BAT-selective agonists result in an increased capacity for DIT and reductions in energetic efficiency. However, it is worth pointing out that the converse also holds true. For example, diet-induced increases in BAT activity (cafeteria-feeding) improve cold tolerance and delay the onset of shivering in cafeteriafed rats exposed acutely to the cold (Rothwell \& Stock, 1980).

Most animal models of obesity have now been shown to exhibit reduced or defective brown fat thermogenesis. Of these the genetically obese (ob/ob) mouse and $(f a / f a)$ Zucker rat and the hypothalamic obesity produced by lesions of the ventromedial hypothalamus have been studied most intensively. The reduced capacity for DIT and its relation to BAT was perhaps best demonstrated in several studies on ob/ob mice conducted by Trayhurn and co-workers (Thurlby \& Trayhurn, 1980; Trayhurn et al. $1982 b$ ). One of these (Thurlby \& Trayhurn, 1980) demonstrated a marked reduction in thermogenesis, BAT blood flow and oxygen extraction of mice injected with noradrenaline, and similar results have been obtained with tissue blood flow studies in Zucker ( falfa) rats (Wickler et al. 1982). Adrenalectomy was later found completely to restore BAT blood flow of Zucker rats to normal values, and this was accompanied by a normalization of the rats' capacity for thermogenesis (Wickler et al. 1986).

There is now a considerable amount of evidence to show that the impaired BAT activity of these obese animals is specifically related to their reduced thermogenic response to dietary stimuli, since they appear quite capable of activating BAT in response to cold exposure, albeit somewhat sluggishly at times (Hogan \& Himms-Hagen, 1980). It is now apparent that the hypothalamic control of BAT in response to cold and diet involves different neural pathways (Rothwell et al. 1988), and it is this selectivity and the effects of hypothalamic manipulations on body composition that provides some of the strongest arguments for a significant role for BAT in DIT and the regulation of energy balance.

Other factors that reduce BAT activity are food restriction (Rothwell \& Stock, 1982c; Hayashi \& Nagasaka, 1983), force-feeding by gastric intubation (Rothwell \& Stock, 1984), heat acclimation (Rothwell \& Stock, 1986b) and lactation (Trayhurn et al. 1982a). All these are associated with reduced levels of DIT and high energetic efficiency, but perhaps some of the best evidence comes from those studies where the impact of BAT on DIT and energy balance have been assessed by surgically removing or denervating some of the tissue (mainly the interscapular BAT). One study (Connolly et al. 1982) found that removal of the interscapular BAT depot produced a significant increase in body fat content, while another (Dulloo \& Miller, 1984) found that bilateral denervation produced a $50 \%$ increase in net efficiency. These effects on energy metabolism and body composition are more remarkable than they might seem, since the animals were fed on ordinary stock diet. The level of DIT in stock-fed rodents is normally very low (cf. hyperphagic animals) and one would not expect to see such a noticeable impact on energy metabolism following the removal of only $20-25 \%$ of total BAT. Clearly, a total 
BAT lipectomy (if it were possible) would have a very pronounced effect on energy balance.

A very novel approach was adopted by Moore et al. (1986) when they reduced the size of litters to produce overfed neonatal rats, and found that this increased the neonates' maximal thermogenic response to acute cold exposure. However, this effect of overfeeding was significantly reduced in pups that had BAT lipectomies at $2 \mathrm{~d}$ of age. BAT lipectomy, however, may not always result in the expected change in DIT or energy balance if the remaining brown fat depots undergo compensatory hypertrophy. We have found recently (N. J. Rothwell and M. J. Stock, unpublished results) that removal of large amounts of BAT (40\% of total) in rats fed on a low-protein diet had an initial, transient effect on levels of DIT, but this soon disappeared due to compensatory hypertrophy and increases in mitochondria GDP-binding in the remaining depots. This compensation in animals with a strong dietary stimulus for thermogenesis suggests that BAT plays a crucial role in the thermogenic response to dietary manipulations.

\section{$D I T$ and $B A T$ in natural conditions}

There are various natural, non-experimental situations where BAT activity appears to be related to levels of DIT. For example, there is an age-related decline in the capacity for DIT that corresponds with an increase in adiposity, and this coincides with a decrease in BAT activity (Rothwell \& Stock, 1983; Simpson et al. 1986). There are also marked strain differences in BAT activity that correlate with the capacity for DIT, or the predisposition to obesity (Rothwell et al. 1982; Fisler et al. 1987). Differences between species are particularly obvious when comparing small laboratory or wild animals with some of the larger domesticated animals (e.g. pigs, sheep, cattle). In these large mammals, BAT disappears very rapidly after birth (Rothwell \& Stock, 1985b), and it is perhaps not surprising that the modern varieties of these species are noted for their high feed efficiency and fatness.

A particularly significant observation is the large amounts of brown fat that are found in fruit-eating bats (Pteropopidae macroglossus) (Okon, 1980) and marmosets (Callithrix jacchus) (Rothwell \& Stock, 1985a). Both species live in tropical or subtropical regions where there is little or no thermoregulatory requirement for BAT and NST. However, both species are fructivores and consume a diet that contains very little protein. Thus, it could be argued that in the absence of cold-stress, the only possible function for these large BAT depots (particularly in adult marmosets) is as an effector of DIT. These animals are required to consume large quantities of food in order to meet their protein requirements (the fruit-bat consumes $1.0-1.5 \mathrm{MJ} / \mathrm{kg}^{0.75}$ body-weight per $\mathrm{d}$ (Thomas, 1984)), but their high capacity for DIT would allow them to dispose of the excess non-protein energy.

\section{Conclusions}

Adaptive DIT represents a loss of metabolizable energy as heat, resulting in a decrease in energetic efficiency. It is stimulated by hyperphagia and nutrient imbalances, but is highly variable, depending on age, genotype, environmental temperature and other factors. DIT is associated with increased brown fat activity, and produces chronic, adaptive changes in BAT structure and biochemical function similar to those seen in animals exhibiting NST. Studies on the quantitative contribution of BAT thermogenesis to DIT have relied on in vivo measurements of $\mathrm{O}_{2}$ extraction, or on observing the effects on energy balance of partial removal, or sympathectomy of small depots. The interpret- 
ation of many of these studies can be difficult, but the overall conclusion is that BAT can make a major contribution to adaptive DIT, and that failure to activate BAT is a common feature of most examples of obesity.

\section{REFERENCES}

Arch, J. R. S. (1989). Proceedings of the Nutrition Society 48, 215-223.

Arch, J. R. S. \& Ainsworth, A. T. (1983). American Journal of Clinical Nutrition 38, $549-558$.

Arch, J. R. S., Ashworth, A. T., Cawthorne, M. A., Piercy, V., Sennitt, M. V., Thody, V. E., Wilson, C. \& Wilson, S. (1984). Nature 309, 163-165.

Ashwell, M., Rothwell, N. J., Stirling, D., Stock, M. J. \& Winter, P. D. (1984). Proceedings of the Nutrition Society 43, 147A.

Brooks, S. L., Rothwell, N. J. \& Stock, M. J. (1982). Quarterly Joumal of Experimental Physiology 67, 259-268.

Brooks, S. L., Rothwell, N. J., Stock, M. J., Goodbody, A. E. \& Trayhurn, P. (1980). Nature 286, 274-276.

Connolly, E., Morrisey, R. D. \& Carnie, J. A. (1982). British Journal of Nutrition 47, 653-658.

Cox, J. E. \& Lorden, J. F. (1986). American Joumal of Physiology 250, R1108-R1116.

Dulloo, A. G. \& Miller, D. S. (1984). Canadian Joumal of Physiology and Pharmacology 62, 235-240.

Emery, P. W., Rothwell, N. J. \& Stock, M. J. (1983). Bioscience Reports 3, 569-575.

Falcou, R., Bouillaud, F., Mory, G., Apfelbaum, M. \& Ricquier, D., (1985). Biochemical Journal 231, 241-244.

Fisler, J. S., Lupien, J. R., Wood, R. D., Bray, G. A. \& Schemmel, R. A. (1987). American Journal of Physiology 253, R756-R762.

Foster, D. O. \& Depocas, F. (1980). Canadian Journal of Physiology and Pharmacology 58, 1418-1425.

Foster, D. O. \& Frydman, M. L. (1978). Canadian Journal of Physiology and Pharmacology 56, 110-122.

Glick, Z., Wickler, S. J., Stern, J. S. \& Horwitz, B. A. (1984). Journal of Nutrition 114, 1934-1939.

Hayashi, M. \& Nagasaka, T. (1983). American Joumal of Physiology 245, E582-E586.

Hervey, G. R. \& Tobin, G. (1983). Clinical Science 64, 7-18.

Himms-Hagen, J., Triandafillou, J. \& Gwilliam, C. (1981). American Journal of Physiology 241, E116-E120.

Hogan, S. \& Himms-Hagen, J. (1980). American Journal of Physiology 239, E301-E309.

Holloway, B. R. (1989). Proceedings of the Nutrition Society 48, 225-230.

Holt, S. \& York, D. A. (1982). Biochemical Journal 280, 819-822.

Ma, S. W. Y., Foster, D. O., Nadeau, B. E. \& Triandafillou, J. (1989). Canadian Journal of Physiology and Pharmacology (In the Press).

Ma, S. W. Y., Nadeau, B. E. \& Foster, D. O. (1987). Canadian Journal of Physiology and Pharmacology 65, $1802-1804$.

Marchington, D., Rothwell, N. J., Stock, M. J. \& York, D. A. (1986). American Journal of Physiology 250, E362-E366.

Maxwell, G. M., Nobbs, S., Fourie, F. \& Bates, D. J. (1988). Clinical and Experimental Pharmacology and Physiology 15, 391-400.

Moore, B. J., Stern, J. S. \& Horwitz, B. A. (1986). American Journal of Physiology 251, R518-R524.

Nedergaard, J., Raasmaja, A. \& Cannon, B. (1984). Biochemical and Biophysical Research Communications 3, 1328-1336.

Nicholls, D. G. (1979). Biochimica Biophysica Acta 549, 1-29.

Okon, E. E. (1980). In Proceedings of Sth International BAT Research Conference, pp. 91-93 [D. E. Wilson and A. L. Gardener, editors]. Lubbock: Texas Technical Press.

Rothwell, N. J., LeFeuvre, R. A. \& Stock, M. J. (1988). In Obesity in Europe 88, [P. Bjorntorp and S. Rossner, editors]. London: Libbey.

Rothwell, N. J., Saville, M. E. \& Stock, M. J. (1982). Journal of Nutrition 112, 1515-1524.

Rothwell, N. J. \& Stock, M. J. (1979). Nature 281, 31-35.

Rothwell, N. J. \& Stock, M. J. (1980). Canadian Joumal of Physiology and Pharmecology 58, 842-848.

Rothwell, N. J. \& Stock, M. J. (1981a). Pfiugers Archiv 38s, 237-242.

Rothwell, N. J. \& Stock, M. J. (1981b). In Contributions to Thermal Physiology, pp. 511-513 [Z. Szelenyi and M. Szekely, editors]. Oxford: Pergamon.

Rothwell, N. J. \& Stock, M. J. (1982a). Joumal of Nutrition 112, 426-435.

Rothwell, N. J. \& Stock, M. J. (1982b). British Journal of Nutrition 47, 461-471. 
Rothwell, N. J. \& Stock, M. J. (1982c). Bioscience Reports 2, 543-549.

Rothwell, N. J. \& Stock, M. J. (1983). International Journal of Obesity 7, 583-589.

Rothwell, N. J. \& Stock, M. J. (1984). Journal of Nutrition 114, 1965-1970.

Rothwell, N. J. \& Stock, M. J. (1985a). Comparative Biochemistry and Physiology 81A, 683-686.

Rothwell, N. J. \& Stock, M. J. (1985b). Comparative Biochemistry and Physiology 82A, 745-751.

Rothwell, N. J. \& Stock, M. J. (1986a). In Brown Adipose Tissue, pp. 269-298 [P. Trayhurn and D. G. Nicholls, editors]. London: Edward Arnold.

Rothwell, N. J. \& Stock, M. J. (1986b). British Journal of Nutrition 56, 123-129.

Rothwell, N. J., Stock, M. J. \& Sudera, D. K. (1985). European Journal of Pharmacology 125, 313-323.

Rothwell, N. J., Stock, M. J. \& Sudera, D. K. (1987). Proceedings of the Nutrition Society 46, 92 A.

Rothwell, N. J., Stock, M. J. \& Tyzbir, R. S. (1983). Metabolism 32, 257-261.

Rothwell, N. J., Stock, M. J. \& Wyllie, M. G. (1984). Pflugers Archiv 402, 325-329.

Simpson, M. L. F., Cooney, I. G. J., Caterson, D. \& Newsholme, E. A. (1986). Biochemical and Biophysical Research Communications 140, 419-426.

Smith, C. K. \& Romsos, D. R. (1984). Metabolism 33, 853-857.

Stirling, J. L. \& Stock, M. J. (1968). Nature 220, 801-802.

Thomas, D. W. (1984). Physiological Zoology 57, 457-467.

Thurlby, P. L. \& Trayhurn, P. (1980). Pfligers Archiv 385, 193-201.

Trayhum, P., Douglas, J. B. \& McGuckin, M. M. (1982a). Nature 298, 59-60.

Trayhurn, P., Jones, P. M., McGuckin, M. M. \& Goodbody, A. E. (1982b). Nature 295, 323-325.

Tulp, O. L. (1981). International Journal of Obesity 5, 579-591.

Wickler, S. J., Horwitz, B. A. \& Stern, J. S. (1982). International Journal of Obesity 6, 481-490.

Wickler, S. J., Horwitz, B. A. \& Stern, J. S. (1986). American Joumal of Physiology 251, R851-R858.

Young, J. B., Saville, M. E., Rothwell, N. J., Stock, M. J. \& Landsberg, L. (1982). Journal of Clinical Investigation 69, 1061-1071. 